\title{
A reflection on medical versus aesthetic dermatology: Case series.
}

\author{
César Bimbi ${ }^{{ }^{*}}$ and Lorenzo Martini ${ }^{2}$
}

${ }^{1}$ Dermatological Committee of State Medical Council of Rio Grande do Sul Brazil, Brazilian Society of Dermatology, Brazil ${ }^{2}$ Department of Pharmaceutical Biotechnologies, University of Siena, Italy

\begin{abstract}
The intensity of interest in cosmetology overshadows investigative side of clinical dermatology. In this report, we show clinical cases where the need for attention and investigative interest is essential. Is it possible to reconcile the practice of cosmetology with clinical dermatology?
\end{abstract}

Keywords: Sarcoidosis; Corticosteroids; Vitiligo; Tinea versicolor.

\section{Introduction}

New techniques of cosmiatry and rejuvenation, hunted avidly by a large portion of the population have been changing dermatology over the last years. The benefic effect of cosmiatry cannot be denied nor the immense benefit for self-esteem and correction of aesthetic defects [1]. But it is also impossible to deny that this dermatological subspecialty robbed the attention and interest of clinical or medical dermatology.

Skin mirror internal diseases. Various systemic illnesses manifest in the skin and skin offers the advantage of easy access for biopsy and the possibility of early diagnosis of systemic diseases and so better prognosis. Solving mystery puzzles on complex or very rare diseases and syndromes makes the beauty of dermatology [2]. Fascinating medical cases where the general clinicians had already given up were elegantly unveiled by dermatologists with no need of anything but close inspection of tiny, otherwise unimportant lesions that often represents the tip of the iceberg [3]. We describe below clinical cases that demonstrate the need for investigation and the difficulty of some diagnoses, and also the gratification of a puzzle solved.

\section{Case Reports}

\section{Case 1:}

A 35 years old female presented with asymptomatic nonprogressive hyperpigmented flat lesions over the left side of the neck for the past 1 month. There was no preceding history of topical applications or use of perfumes or fragrance. 28-yearold female patient came to the office complaining of a "minor irritation" on her left eyebrow that had started 6 months earlier. Biopsy showed granulomatous features of sarcoidosis. Under subsequent systemic investigation stage II pulmonary sarcoidosis with reticulo-endothelial involvement as enlarged mediastinal lymph nodes was found (Figure 1).

The early diagnosis was of substantial benefit to the patient in that with just $40 \mathrm{mg}$ of prednisone for a short period of time, respiratory symptoms disappeared..

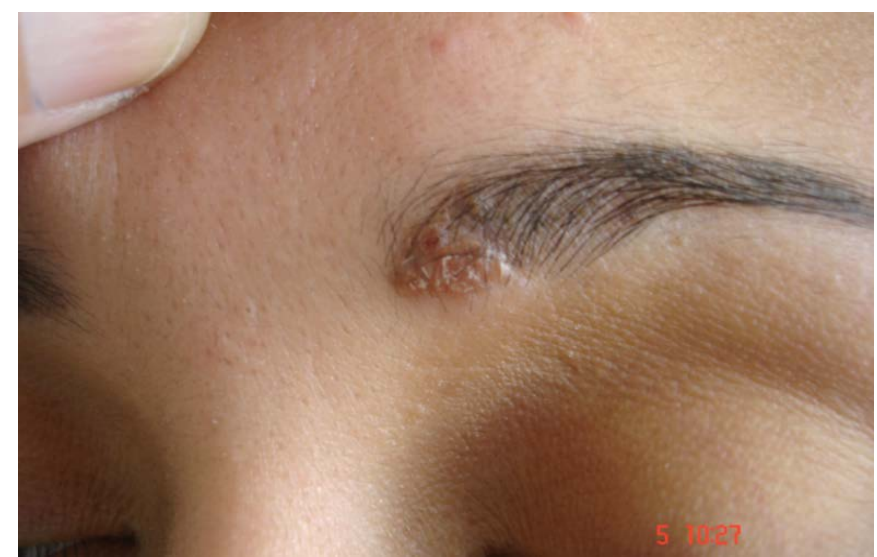

Figure 1. From a small discrete and asymptomatic $5 \mathrm{~mm}$ infiltrated apple jelly-coloured seborreic-like papule a systemic disease was revealed.

\section{Case 2:}

56-year-old male patient complaining of a 2 year history of facial eruptions (Figure 2a). "An allergy" that had initiated by the nose which was treated firstly with antibiotics for acne rosacea, but with no improvement led to systemic corticosteroids under suspicion of systemic lupus. Microscopic $\mathrm{OH}$ examination showed hyphae and oral itraconazole and topical ciclopirox cleared the lesions quickly (Figure 2b).

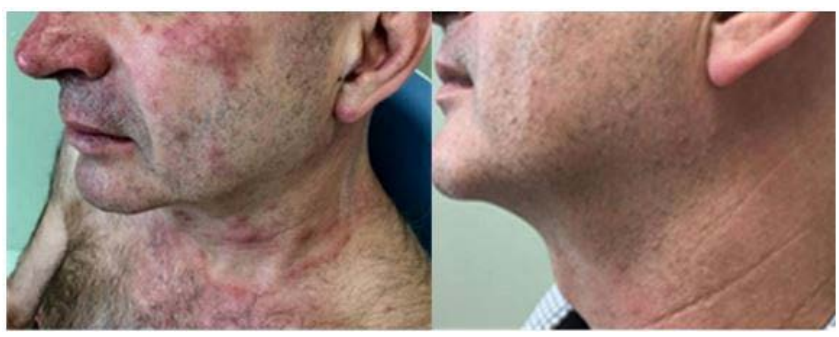

Figure 2. Lupus-like lesions that a more detailed inspection ended up revealing itself as tinea faciei. 


\section{Case 3:}

14 years old girl, came with spot around mouth (Figure 3a) emerging after sun exposure, and an obvious suspicion of perioral vitiligo was done, but in the hypochromic area close inspection showed fine furfuraceous scaling. Mycological exam revealed spores and filaments of Malassezia furfur (Figure $3 b)$. Now improving with cyclopirox-olamine cream. Tinea versicolor was the diagnosis.

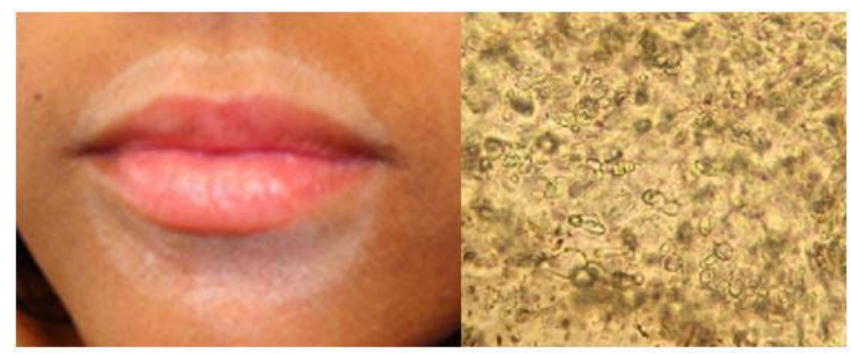

Figure 3. Perioral hypochromic area with fine furfuraceous scaling showing Malassezia spores and filaments.

\section{Case 4:}

11 year old boy had this nevocytic nevus (congenital) (Figure 4a) and "started another one "very similar macule on palm after beach summer season. Mycological exam revealed instead of a new nevus it turned out to be a case of Tinea nigra palmaris. This mycosis is more prevalent among young peoplecoming home from beaches.

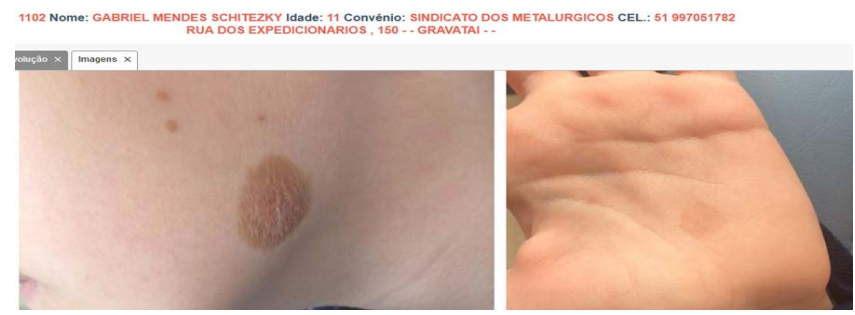

Figure 4. Nevocytic Nevus on face since birth and pigmented macule on palm.

\section{Conclusion}

Not a few times the clinical dermatologist worries that the intensity of interest in the cosmetology will overshadow the investigative side of the specialty. In every dermatologist, there should be something of the detective of diseases to put the difficult to diagnose pieces of a disease together by posing the right questions at the right time, and an open mind and deductive reasoning with attention to details. Recent over emphasis of dermatology on cosmetology may lead to lack of interest on the investigative aspects. Although aesthetic procedures may reach more economical rewarding results it may be wiser to exercise both parts of dermatology at least while cosmiatry don't get its independence.

\section{References}

1. Dubertret L. Dermatology, cosmetology and aesthetic medicine. La Revue Du Praticien. 2000; 50: 6-7.

2. Oderwald A, Sebus J. The physician and Sherlock Holmes. J Royal Society Med. 1991;84:151-152.

3. Smith E, Beerman H. Sherlock Holmes and dermatology. Int J Dermatol. 1977; 16: 433-438.

\section{"Correspondence to}

Dr. César Bimbi,

Member of Dermatological Committee of State Medical Council of Rio Grande do Sul Brazil, Brazilian Society of Dermatology,

Brazil,

Tel: (21) 2253-6747

E-mail: cbimbi@terra.com.br 